\title{
Opportunities for language enhancement in a learning environment designed on the basis of the theory of didactical situations
}

\author{
Frode Rønning ${ }^{1}$
}

Accepted: 23 October 2020 / Published online: 12 November 2020

(c) The Author(s) 2020

\begin{abstract}
This paper is based on data from two teaching sequences in primary school that are designed using principles from the theory of didactical situations (TDS). The following research question is addressed: "What opportunities can a teaching design based on TDS give a teacher to gain insight into pupils' language use, and to use this insight to establish shared, and mathematically acceptable, knowledge in a group of primary school pupils?" Empirical data from one teaching sequence on geometrical shapes and another teaching sequence on combinatorial problems are used to answer this question. The research shows that a sharp focus on well-defined learning goals does not limit the pupils' possibilities in expressing their thoughts and ideas in their own language. The research also shows that despite clear learning goals, the teacher has rich opportunities to build on pupils' language to connect everyday and scientific language for the purpose of developing a mathematically accepted discourse.
\end{abstract}

Keywords Theory of didactical situations · Didactical engineering $\cdot$ Language development $\cdot$ Geometry $\cdot$ Combinatorics

\section{Introduction}

This paper is based on a longitudinal research project, Language Use and Development in the Mathematics Classroom (LaUDiM), carried out in collaboration between researchers at the university and teachers at two primary schools. Classroom sessions were designed by the researchers and the teachers in collaboration and led by the teachers, with researchers present in the classroom. The design of the classroom sessions was guided by principles from the Theory of Didactical Situations, TDS (Brousseau 1997) and the research methodology used was inspired by didactical engineering (Artigue 2015). A central aim of the project LaUDiM was to develop a successful learning culture in early learning of mathematics, with special emphasis on language development. This aim includes developing pupils' proficiency in a broad register of mathematical discourse with well-defined learning goals for each classroom session. The aim also includes developing teachers' proficiency in orchestrating the mathematics classroom in ways that would

Frode Rønning

frode.ronning@ntnu.no

1 Department of Mathematical Sciences, Norwegian University of Science and Technology, Trondheim, Norway contribute to the intended learning for the pupils. More specifically, the aim for the pupils can be formulated as developing their proficiency to express and connect mathematical ideas using a variety of semiotic representations, as well as developing their proficiency to reason, argue and justify their solutions. TDS was chosen as a framework for designing teaching sequences for the following reasons. A characteristic feature of TDS is a sharp focus on the mathematical knowledge to be learnt. A design based on TDS is structured in phases in which pupils are encouraged to discuss and to justify their solutions, as well as phases where the teacher is actively engaged in connecting everyday and scientific language (Brousseau 1997). These features were considered to fit well with the aims of the project. Based on examples from the classroom, the paper shows how the design provides opportunities for the pupils to develop a mathematically sound language repertoire, and also how it provides opportunities for the teacher to support the pupils' language development.

Erath et al. (2021) list six design principles for instructional approaches, one of which is to enhance rich discourse practices and another of which is to connect registers and representations. The research reported in this paper links to both of these design principles. Furthermore, Erath et al. discuss teaching practices for enhancing language in 
mathematics classrooms with a special focus on teacher moves. Two of these teaching practices are to plan and prepare collective discussions that focus on mathematical concepts, and to understand and connect students' ideas to mathematics concepts. The results in this paper show how a TDS-based design can be an effective basis for such teaching practices. A teaching sequence based on TDS should always be designed with a specific piece of knowledge in mind. The results show that this is not in contradiction to building on pupils' own language. On the contrary, the pupils' own language turns out to be very important for the teacher, who, through necessary modifications, guides the pupils in establishing a mathematically acceptable language.

Research on mathematics and language has traditionally focused on three major objects of study: the language of the learner, the language of the teacher and the classroom, and the language of mathematics (Schütte and Planas 2018). Ingram et al. (2020) wrote that recently one has observed a shift towards a more integrated understanding in which the focus is increasingly on the interactions between teachers, students and mathematics. This paper follows the trend indicated by this shift, as it is the interaction between the language of the pupils, of the teacher and of mathematics that is the main object of study.

Howe and Abedin (2013) made a review of 225 studies of classroom dialogue that were conducted over a period of almost 40 years. They found that classroom dialogue is based mainly on a teacher-student IRF pattern, and some student-student interaction, and that this situation is relatively stable over the whole period of investigation. One of the messages in their paper is that not much is known about whether certain modes of organisation are more beneficial than others. Muhonen et al. (2016) examined what types of dialogic teaching patterns could be identified in the early years of schooling, and how teachers scaffolded pupils' participation and shared understanding through dialogic teaching. Their study covered preschool to Grade 2 in Finland, in literacy, science and mathematics. In their findings, they distinguished between teacher-initiated patterns and child-initiated patterns, and within each of these categories they distinguished between dialogues of 'moderate' and of 'high' quality. In the teacher-initiated patterns, the teacher generated the strategies and played the role of a leader, who actively supported and maintained the dialogue. The researchers observed large differences between subjects, and dialogic episodes were least often identified in mathematics lessons. The authors claimed that little is known about concrete teaching practices that facilitate high-quality classroom dialogue, especially among younger children.

My aim is to contribute to the knowledge base on teaching practices that facilitate classroom dialogue with emphasis on interactions between teacher, students and mathematics, by investigating a design based on TDS. Since TDS addresses a deep concern with the mathematical knowledge at stake, the mathematical content in the teaching sessions play an important role. Relevant theory that takes into account the mathematical content is therefore introduced. In order not to focus on too narrow a perspective, I have chosen episodes from two teaching sequences, dealing with different areas of mathematics and involving pupils at different ages. One teaching sequence, on geometrical shapes, was carried out in Grade 2 (pupils of ages 7-8), and the other, on combinatorial problems, in Grade 4 (ages 9-10). With this span in topics and age, it is reasonable to anticipate that the affordances of the design are neither connected to a particular topic, nor to a specific age. In both teaching sequences the pupils were given tasks to carry out without being given instructions for solving the tasks, and I investigated to what extent the TDS design gives opportunities for language development. The exposition of the paper is guided by the following research question:

What opportunities can a teaching design based on TDS give a teacher to gain insight into pupils' language use, and to use this insight to establish shared, and mathematically acceptable, knowledge in a group of primary school pupils?

\section{Theoretical framework}

\subsection{Sociocultural theory and the role of language}

The project LaUDiM is based on a sociocultural view on learning, seeing language as important for learning (Vygotsky 1978, 1987; Wertsch 1991). Language is seen as central for meaning making and for conceptual understanding, and the development of mathematical discourse is seen as necessary for competent participation in mathematical practices (Moschkovitch 2015). Conceptual knowledge and understanding (Hiebert and Carpenter 1992; Hiebert and Lefevre 1986) is characterised by a rich network with multiple connections between concepts and semiotic representations. Prediger and Zindel (2017) link conceptual understanding to language by showing how language proficiency is crucial for conceptual understanding. For learners to become competent participants in mathematical practices, they have to switch from an everyday language register to a mathematically accepted, scientific language register. According to Vygotsky (1987), scientific concepts develop differently from everyday concepts and the development of scientific concepts depends on a particular level of maturation of spontaneous concepts. Traditionally, the teacher would provide the scientific terms in an introduction to a topic and the role of the pupils would be to adopt the terms and use them in their mathematical activities, a procedure described by Bruder 
and Prescott (2013) as 'the Rule and Example approach'. This approach may lead to a gap between the everyday and the scientific concepts, hindering the creation of the network necessary for conceptual understanding. Vygotsky wrote that "scientific concepts can arise in the child's head only on the foundation provided by the lower and more elementary forms of generalization which previously exist" and that " $[t]$ hey cannot simply be introduced into the child's consciousness from the outside" (Vygotsky 1987, p. 177). Therefore, the teacher has to guide the pupils' development of language in a direction which complies with established standards, at the same time respecting pupils' own language use and development. In the next section I give an account of TDS, introducing central concepts that are used later.

\subsection{The theory of didactical situations (TDS)}

TDS (Brousseau 1997) is based on creating a situation with a problem to be solved and a particular piece of mathematical knowledge to be developed, the target knowledge. A teaching sequence based on TDS consists of different phases, namely, adidactical phases where there is little or no intervention from the teacher, and didactical phases, where the teacher is more active and acts with didactical intentions, i.e., intentions that the pupils should learn something specific, the target knowledge. An adidactical situation is a situation in which pupils take a mathematical problem as their own and try to solve it without teacher guidance. The pupils work with the problem in the milieu provided, i.e., the elements of the material and intellectual reality on which the pupils act when solving the problem. Ideally an appropriate adidactical milieu provides feedback to the pupils, feedback which reveals whether their responses are adequate with respect to the knowledge at stake. The knowledge should be entirely justified by the internal logic of the situation and should be possible to obtain without didactical reasoning (Brousseau 1997, p. 30). To accomplish this, the milieu should be designed with conditions that encourage the pupils to choose one strategy over another, and the chosen strategy should lead to development of the target knowledge (Strømskag 2017 , p. 911). In practice, it has turned out to be challenging to design a milieu giving adequate feedback, so although striving for adidacticity, this is hard to maintain (GonzálezMartín et al. 2014; Måsøval 2013).

A teaching sequence starts with the devolution phase, where the teacher transfers responsibility for solving the problem to the pupils. This phase is followed by four other phases, namely, action, formulation, validation, and institutionalisation. Ideally, the first three of these phases are adidactical, whereas the last phase is didactical. In the action phase the pupils engage with the given problem on the basis of its inner logic, without teacher intervention. In the formulation phase the pupils try to formulate a strategy enabling somebody else to operate on the milieu. In the validation phase the pupils attempt to explain some phenomenon or verify a conjecture, while being encouraged by the teacher to use more precise mathematical language. In the institutionalisation phase the teacher connects the knowledge built by the pupils to the scholarly and decontextualised forms of knowledge aimed at by the institution (Artigue et al. 2014; Brousseau 1997; Strømskag 2017). Strømskag writes that in the validation phase "the teacher's role is to ... (ideally) intervene only to structure the debate and try to make the students express themselves in more precise mathematical language" (Strømskag 2017, p. 911). Her use of the word 'ideally' indicates that often the validation phase has clear didactical traits, usually considered by the teacher as necessary because of insufficient feedback from the milieu. As acknowledged by Artigue et al. (2014, p. 53) devolution is difficult and also paradoxical because, on the one hand the teacher should have a precise learning aim in mind, but on the other hand she should not tell the students what to do, because if she does, the student will not learn. Students' learning in TDS is seen as a combination of adaptation and acculturation (Artigue et al. 2014). Adaptation happens when "the student learns by adapting herself to a milieu which generates contradictions, difficulties and disequilibria, rather as human society does" (Brousseau 1997, p. 30). However, Artigue et al. claim that adaptation is not enough: to link students' constructions with institutionally accepted knowledge, also acculturation is necessary (p. 49). To establish this link, a didactic intervention by the teacher is necessary. This link can be compared to the encounter of everyday and scientific language as described by Vygotsky (1987) and it is in line with teaching practices involving the connection of students' ideas to mathematics concepts and encouraging student participation in demanding discourse (Erath et al. 2021). To the extent that this practice is successful, it can be seen as an example of a teaching practice that facilitates high-quality classroom dialogue (Muhonen et al. 2016) and an example of interactions between teachers, students and mathematics (Ingram et al. 2020).

\section{Contextualisation of the study}

Language as a topic of research in mathematics education has a long history (see Erath et al. 2021, for an overview). Language is seen to be crucial for developing conceptual knowledge and conceptual understanding in mathematics (Hiebert and Carpenter 1992; Hiebert and Lefevre 1986; Moschkovich 2015; Prediger and Zindel 2017). In the process of developing the network characterising conceptual knowledge and understanding, the ability to switch between, and to connect, registers and representations is important (Prediger and Wessel 2013). According to Erath et al. 
(2021) there is a lack of empirical foundation for instructional approaches that support language in the mathematics classroom. This paper contributes with results from an instructional approach based on TDS. To better see the specific traits of TDS, in this section I compare TDS to other instructional approaches.

One of the central components of TDS is the target knowledge, and this should be necessary, or in some sense optimal, to solve the task at hand (Strømskag 2017). Therefore, in a design based on TDS, students are not working with openended problems, as tends to be the case, for example, in the problem-solving tradition. Students are expected to build the target knowledge through interaction with the milieu (Artigue and Blomhøj 2013). However, this does not mean that the procedures for arriving at a solution of the task are given. Students are free to explore their own methods, try them out, discuss them amongst one another, and try to convince their peers that a solution is correct, and why it is correct (action, formulation, and validation). The freedom that exists in the adidactical phases justifies the claim that a design based on TDS has possibilities for encouraging active learning, defined by Bonwell and Eison (1991) as "anything that "involves students in doing things and thinking about the things they are doing"' (p. 19). The term active learning was extended by Laursen and Rasmussen (2019) to include a language element by adding that active learning also involves "the explicit expectation that students talk to each other about what they are doing and thinking" (p. 131). Laursen and Rasmussen take active learning as a starting point to define what they see as inquiry in mathematics. They state three characteristic features of inquiry: First, an inquiry-based approach should exhibit a longer-term trajectory with sequences of tasks building towards big ideas. Second, students should be given the opportunity to reinvent mathematics that is new to them, and third, an inquiry-based approach should offer students and instructors the opportunity to develop a critical stance towards previous learning and teaching routines (Laursen and Rasmussen 2019, pp. 131-132). Artigue and Blomhøj (2013) discuss inquiry-based learning (IBL) in connection with other approaches, one of them being TDS. They identify several similarities but also differences. Going back to the historical and philosophical roots of the two approaches, they claim that the philosophy behind IBL leads to a practice of teaching based on projects closely linked to students' life and interests, whereas the philosophy behind TDS leads to careful organisation of students' experiences to make them see the limitation of common sense (Artigue and Blomhøj 2013, p. 800). This aspect is connected to the notion in TDS of overcoming an epistemological obstacle in order to get to the target knowledge. Although the students' work in the adidactical phases has many similarities to an inquiry approach, the problems are mainly under the control of the teacher and developing inquiry habits of mind is not a primary goal (Artigue and Blomhøj 2013, p. 804). The examples in the paper show that the TDS design opens opportunities for an inquiry approach, and that it contains opportunities for reinventing mathematics, despite the clear target knowledge set by the teacher.

The fact that the TDS design involves an a-priori analysis of the target knowledge necessarily places mathematical concepts at the core of a TDS-based design. Mathematical concepts and properties are expressed using language in various forms; words, symbols, signs and algebraic expressions, graphs and other pictorial representations. Traditionally, the teacher would provide the relevant language, and the role of the pupils would be to adopt this language for use in their mathematical activities, as in 'the Rule and Example approach' (Bruder and Prescott 2013). This is not the case in a TDS-based design. Language is developed as part of a practice, in joint meaning making, in which both teachers and pupils take part. Since mathematics is based on definitions and conventions, it is important that mathematical language be developed so as to comply with the established definitions and conventions in order to secure successful communication (Moschkovich 2015). Therefore, the teacher has to guide the pupils' development of language in a direction which complies with established standards. In the examples that I present, the teacher actively uses the pupils' own language, together with her own mathematical and professional knowledge, to guide them towards the use of mathematically acceptable language.

Much of the research on language and mathematics deals with language learners but in my situation, this is not the case. Schütte (2018) writes that "framings of situations that differ from the framing of the teacher ... can be reconstructed not only in children with presumed linguistic deficits but also in children with monolingual and relatively schooled backgrounds" (p. 33). The children in question here belong to this latter category. According to Schütte, these children also need to be introduced to formal and subject-specific mathematical language aspects, with the teacher acting as a linguistic role model (Schütte 2018, p. 34). In an earlier publication, Schütte (2014) claimed that "it is not the mastering of general linguistic competences that is most significant for successful subject learning in mathematics, but the gaining of competences in a subject-related academic language" (p. 924). This claim is supported by results in a recent quantitative study, which showed that monolingual pupils with high language proficiency, indeed gain more from language support than multilingual students (Prediger and Wessel 2018).

\section{Methodological approach}

\subsection{Data collection and analysis}

This paper reports part of a research project, based on data from one of the schools participating in the LaUDiM 
project. The choice of school was made based on the quality of the available data. As mentioned in Sect. 3, the pupils involved are monolingual and the school in question is located in a well-established neighbourhood. The project followed a common structure in terms of planning and developing teaching sequences, and also data collection throughout the whole period that the pupils were followed (2014-2018). The design of each teaching sequence was guided by principles from TDS (Brousseau 1997), strongly inspired by principles from didactical engineering (Artigue 2015). Before a teaching sequence started, teachers and researchers performed a preliminary analysis (epistemological analysis) of the mathematical content at stake. This included common readings dealing with the particular mathematical topic to be worked with in the teaching sequences. For each teaching sequence, the desired target knowledge was decided on. Following the principles of didactical engineering, the preliminary analysis led through didactical transposition to the development of an epistemological model which included the task and the milieu. The task should, after devolution, ideally, require the target knowledge to be developed in order to be solved. The solution of the task should be connected to scholarly and decontextualized knowledge in the institutionalisation phase (Strømskag 2017). One teaching sequence consisted of two-three classroom sessions.

Following the preliminary analysis, teachers and researchers in collaboration, designed the teaching sequences in more detail, designing tasks that were thought to be appropriate for obtaining the target knowledge. The teacher at each school was responsible for the teaching but researchers were also present in the classroom during the sessions, with the possibility of interacting with the pupils. Whole class sessions were video recorded, as well as selected pupils' work in pairs. In each session, two or three pairs of collaborating pupils were video recorded. This limitation was introduced partly in order not to be overloaded with data, and partly because only a limited number of video cameras were available. Pupils were paired by the teacher, based on her knowledge of the pupils. The pairing was based on selecting pupils that were expected to communicate well, and also on a principle of varying from one session to the next, so that the pupils should not feel that only a selected few were participating in the project. Towards the end of the project, the principle of variation was partly abandoned because it was seen as valuable to have data from the same pupils from consecutive sessions. Between the classroom sessions there were brief meetings between the teacher and the researchers who had been present in the classroom, in order to make a preliminary evaluation of the classroom session and to make adjustments for the next session. After a teaching sequence was completed, teachers and researchers met for a preliminary analysis of the sequence. All meetings between teachers and researchers were video recorded. All names used in the paper are pseudonyms.

As a basis for the report of my investigations I use episodes from two different teaching sequences, one on geometrical shapes in Grade 2 and one on combinatorics in Grade 4. These episodes represent a certain span, both in the pupils' age and in the mathematical topics dealt with. This span is chosen in order to show that the affordances of the TDS design are not limited to one particular topic or to one particular age group. Using dialogues and written material from the adidactical phases, I show examples of pupils' own language use, and then excerpts from teacher-pupil interaction in the whole class sessions to show how the teacher built on pupils' language in the institutionalisation phase. Dialogues from the classroom sessions have been transcribed from the video recordings, and later translated from Norwegian into English. In cases where it is important for the analysis to emphasise the meaning of a particular word in Norwegian, the Norwegian word is included in the transcript, in square brackets. Sometimes also the Norwegian word is used directly in the text, with the English translation in regular brackets. For the episode on combinatorial problems, I have used video recordings from pair work on two tasks that were worked with on two different days, hence the pairs were not the same on the 2 days. However, I have tried to follow the same pupils over both days as far as possible. In addition, I have used data from the whole class session in which the teacher draws on what has been done during the work with both tasks.

The research question guiding the paper is about how the teacher can gain insight into pupils' language and how this insight can be used to establish shared, mathematically acceptable knowledge. For the analysis, I examined the data to search for dialogues as well as written material that can provide evidence of pupils' language use and development, and the role of the teacher in this development. I then performed a micro-analysis of the dialogues from the pair-work and from the whole-class sessions to discern features of the design that seem to foster pupils' language development.

Since the mathematical content of the sessions is central, theoretical frameworks to describe the mathematics of the classroom sessions are included. To be able to characterise the issues involved in the pupils' language on geometrical shapes, semiotic theory, in particular Frege's (1892) theory of signs, as well as Fischbein's (1993) notion of figural concepts, will be used. For the lessons on combinatorics, the analysis is based on Vergnaud's (1996) theory of conceptual fields, more precisely his application of this theory on multiplicative structures (Vergnaud 1983). In Sect. 4.2, some important concepts from these two theoretical frameworks are presented. 


\subsection{Mathematical topics}

\subsubsection{Geometrical shapes}

Geometrical concepts have been described by Fischbein (1993) as having a dual nature: they have spatial properties such as shape, position and magnitude, and at the same time they possess conceptual qualities, representing a general idea. Fischbein used the term figural concepts to express the phenomenon that a geometrical figure is at the same time both a visual image as well as an abstract object with conceptual properties. When a pupil draws an image of a square, this particular image will represent the idea of a square, and at the same time it is one specific figure with a specific side length and a specific position on the paper. Following Frege (1892), the word square, seen as a sign in semiotic theory, has a certain sense and a certain reference. ${ }^{1}$ The reference is the object that the sign refers to, e.g., the drawing of the square, and the sense comprises all thoughts and ideas connected to the concept of a square. The visual nature of geometrical concepts, and the abundance of geometrical shapes in everyday life, have as a consequence that children include words for geometrical shapes in their vocabulary at an early age. Therefore, such words can be considered part of their everyday language.

Several terms from geometry have a different sense and a different reference in everyday language compared to precise mathematical language, and these differences may be an obstacle for the meeting of everyday and scientific language. The following are examples of this phenomenon. The principle for naming polygons in Norwegian is the same as in English, based on the number of edges, except that in Norwegian it is not the Greek terms that are used but the Norwegian ones. So, a pentagon is called a femkant, literally 'five-edge'. Words like 'trekant' and 'firkant' (triangle/ Dreieck and quadrilateral/Viereck) are examples of terms that can be considered part of everyday language as they will be known to children before entering school. Another phenomenon in the Norwegian language is that the word 'firkant' in everyday language often is used as synonymous with square, instead of representing a general quadrilateral. So, in everyday language, the word 'firkant' often has both a much more restricted sense and reference than in the mathematical language. One of the tasks of schooling is to introduce pupils to the mathematical language and to ensure that the terms are used in accordance with the existing conventions. The examples show that it is not always easy to detect that words are not used according to the conventions

\footnotetext{
${ }^{1}$ I use the words sense and reference as English translations of Frege's terms Sinn and Bedeutung, according to the translations used by Geach and Black (1960).
}

and, further, it is shown how the TDS design can be helpful for revealing what in this sense can be seen as incorrect language use.

\subsubsection{Combinatorial problems}

Combinatorial problems constitute one class of the large field of multiplicative structures (see, e.g., Greer 1992). Combinatorial problems are known to involve particular challenges; one such challenge, as was pointed out by Shin and Steffe (2009, pp. 170-171), is that these problems involve a new unit, not there from the beginning, and that this unit is of indefinite quantity. Shin and Steffe see combinatorial problems as counting problems, and suggest that the new unit being of indefinite quantity means that it is not clear from the beginning when to stop counting. Therefore, another challenge with combinatorial problems is to develop a stopping strategy (English 1991).

Vergnaud (1983, p. 128) divides the conceptual field of multiplicative structures into three classes: isomorphy of measures, product of measures, and multiple proportions. Isomorphy of measures covers models in which there is a direct proportion between two measure spaces $M_{1}$ and $M_{2}$. Models such as equal groups, multiplicative comparison, as well as rate, in Greer's (1992) classification, fit into this group. Combinatorial problems expressed in terms of a Cartesian product, are of a different nature. Such problems take input from two measure spaces, $M_{1}$ and $M_{2}$, and give the output in a third measure space $M_{3}$. Vergnaud puts such problems in the class product of measures. Product of measures induces a mapping from a product of two given measure spaces into a third measure space $\left(M_{1} \times M_{2} \rightarrow M_{3}\right)$, not present from the beginning. This also illustrates the phenomenon mentioned above that such problems involve a new unit (Shin and Steffe 2009), namely the unit in the measure space $M_{3}$. Children's first encounter with multiplicative problems is often in models belonging to the class isomorphy of measures, such as equal groups. Combinatorial problems come later, and Verschaffel et al. (2020) write that problems built around a Cartesian product situation are by many people not recognised as multiplicative (p. 5). This phenomenon can be seen as an epistemological obstacle, and in the teaching sequence based on combinatorial problems, which is presented in this paper, part of the target knowledge was that the pupils should realise that these problems could be solved using multiplication and represented using rectangular arrays. This representation would then connect combinatorial problems to other multiplicative problems, for example, area problems. 


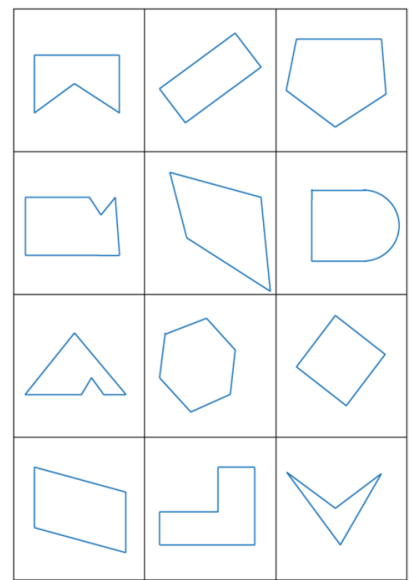

Fig. 1. Shapes to be classified

\section{Analysis of episodes from the teaching sequences}

In the two Sects. 5.1 and 5.2 that follow, I present examples from the two mathematical topic areas to show how the TDS design gave opportunities to gain insight into the pupils' language.

\subsection{Episode 1: Geometrical shapes}

In the first session of the teaching sequence on geometrical shapes, the pupils were given a sheet of paper showing 12 different shapes (Fig. 1), and the task was to sort the shapes into groups as they found appropriate. First, pupils were told to do the sorting individually and afterwards to compare the result of their work in pairs. Then, they were supposed to agree in the pair on a way to sort the shapes and also to agree on an appropriate name for each group. Finally, each group was asked to collect the shapes belonging together, glue them on to a sheet of paper, and then complete the sentence "These are __ because ____, as a justification for their choice of name. These instructions constituted the devolution phase, and in the instructions the phases of action (do the sorting), formulation (compare in pairs and give a name) and validation (justify the choice of name) can be recognised.

Because of the seemingly obvious choice of names for polygons in Norwegian, as explained in Sect. 4.2.1, naming of polygons is not considered to be something to which it is necessary to pay much attention. From the worksheets produced by the pupils in the first classroom session it would seem that there were not many problems with the naming. A typical example could be that pupils had grouped images of quadrilaterals together and filled in the blanks to get the text "These are four-edges because they have four edges" ["Dette er firkanter fordi de har fire kanter"]. This characterization seemed to indicate that the pupils' knowledge about names of geometrical shapes was in line with the institutionally accepted knowledge. However, from the pupils' work in the adidactical phases, the teacher could observe that there were different conceptions of what parts of the polygon the pupils called 'edge' [kant]. Gestures indicated that in some cases pupils said 'edges' [kanter], and indeed pointed to the edges, but in other cases pupils pointed to the vertices ${ }^{2}$ while saying 'edges'. Although the final product of the task, the worksheets, indicated that the sense and reference (Frege 1892) of the words used agreed with the scholarly use of the terms, the discussions showed otherwise. The session had clear target knowledge, correct naming of polygons, and the idea was that this knowledge should be obtained through interaction with the material milieu (the shapes in Fig. 1) without being introduced to definitions of different geometrical shapes in advance. As a result of the TDS-based design, the pupils were free to use their own language in the discussions (adidactical phases) and by observing, and taking part in the discussions, the teacher detected inconsistencies in the sense and the reference of the words being used to characterise the shapes. Based on these observations, the teacher concluded that the target knowledge had not been reached and therefore measures had to be taken to overcome the epistemological obstacle that had been detected. This led to an extended validation phase (with didactical traits), and was followed up in the institutionalisation phase. In the whole class session on the second day of the teaching sequence, the teacher picked pupils that she had observed to have different conceptions of what were the edges, and she asked them to explain their reasoning in front of the whole class. Without any judgement of what was correct or not, the teacher led the discussion in such a way as to reveal that there was indeed a discrepancy in how the terms were used. Excerpts from this discussion are presented below.

One of the shapes causing some confusion, was a nonconvex quadrilateral (shown in the lower right-hand corner in Fig. 1), with one reflex angle and three acute angles. Peter and Mary had placed this shape in a group that they called 'firkanter' (quadrilaterals) and they were asked to come to the board to explain why they had done so. Peter counted one-two-three-four, while clearly pointing to the vertices. When the teacher asked "what is an edge?", Peter answered "that is the pointed parts [spissene]". Fred was also asked to come to the board to show the edges, and using a rectangle as an example, he counted one-two-three-four, pointing at the edges. Now, having disclosed an obvious contradiction

\footnotetext{
2 The Norwegian language has no precise scientific word for vertex; the word which is used is 'hjørne', which means corner, and this word is used both in mathematics and in everyday language.
} 
in the use of the word 'edge' [kant] among the pupils, the teacher initiated a discussion in the class.

Teacher: What is the difference between what Peter did and what Fred did?

Megan: Fred counted the lines [strekene] and Peter counted the pointed parts [spissene].

Teacher: So, actually we did not quite agree on what an edge really is.

The teacher had also observed that the word 'hjørne' (vertex, corner) was used in the discussions, although much less frequently than 'kant' (edge). In the further discussion it became clear that some of the pupils used the word 'hjørne' for vertex when seeing the vertex from the inside, while using the word 'kant' (edge) when seeing the vertex from the outside. The choice of word sometimes also depended on the size of the angle at the vertex. For example, the pupil Christian referred to the reflex angle in the non-convex quadrilateral as a 'hjørne' and to the acute angles as 'kanter' (edges). This discussion showed that both the sense and the reference (Frege 1892) for the words 'kant' (edge) and 'hjørne' (vertex, corner) differed among the pupils. The teacher then decided to make a definition by referring to "what the mathematicians have decided". She held up a rectangular sheet of paper (A4) and said: "Corner (vertex), that is where two sides meet. When we talk about edge, we can also call this the side-edge [sidekant], and where two edges meet, that is a vertex [hjørne]. There is the vertex [hjørne] (pointing to a vertex of the sheet)".

It seemed that the term 'kant' was used in the pupils' discourse to denote something sharp, "the pointed parts [spissene]", when referring, for example, to the vertices of a convex polygon, seen from the outside. In everyday language also, the word 'kant' (edge) often indicates something sharp. The term 'hjørne' was used to a much lesser extent, but if used, it was often with the sense that a 'hjørne' (corner) is a spacious area. This is in accordance with the everyday use of the word in expressions like "sitting in the corner". Using the language of Frege (1892), this shows that the sense and reference of the terms 'kant' and 'hjørne' in the pupils' discourse do not comply with the mathematical discourse. Since, for a polygon, the number of vertices equals the number of edges, this discrepancy in sense and reference would not appear from the pupils' written explanations, and it would probably also not appear if the pupils were just given the definition, linking the name of the polygon to the number of edges.

The TDS design allowed, and even encouraged, the pupils to use their own language when solving the task they had been given. The material milieu made it possible for the pupils to be occupied with the task without much teacher instruction, which allowed the teacher to observe the pupils' language use. These observations revealed a use of the terms
How many different gingerbread biscuits can we make if we have cutters in these four shapes

'kant' and 'hjørne' not in accordance with common mathematical usage. Whole class discussions in the validation phase confirmed these observations and exposed the nonconsistent use of the terms. This discrepancy motivated the need to agree on the sense and reference of the words in order to ensure successful communication and led the teacher to introduce a definition in the institutionalisation phase.

\subsection{Episode 2: Combinatorial problems}

This episode is taken from one of several teaching sequences dealing with multiplicative structures. When the pupils were in Grade 4 they were given combinatorial tasks, as usual throughout the project, without being presented with a method for solving the tasks. Two tasks are shown in Figs. 2 and 3 below. The tasks were worked with on two separate days within the same week. For some of the pupils, Task 1 was extended to include more shapes and more colours in order to provide greater challenges.

Both tasks fall within the model product of measures (Vergnaud 1983), a model that involves a mapping from a product of two measure spaces into a third measure space, i.e. $M_{1} \times M_{2} \rightarrow M_{3}$. In Task $1 M_{1}$ contains shapes, $M_{2}$ contains colours, and $M_{3}$ contains biscuits. In Task $2 M_{1}$ contains trousers, $M_{2}$ contains sweaters, and $M_{3}$ contains days. It turned out that the pupils chose representations that on the surface looked rather different in the two tasks. Also, when working with Task 2 they did not make any reference to what they had done in Task 1 two days before. The solutions shown in Figs. 4 and 5 are examples of how the pupils dealt with Task 1, and the drawing in Fig. 6 is a typical example of a solution to Task 2 .

In Fig. 4 the different colours are represented by coloured disks and one can see arrows from the disks to the coloured shapes in three rows. The row that I have marked with a yellow frame was drawn first. The drawing is not complete with all arrows and colours, but one can see 12 shapes. Figure 5 shows a solution of Task 1 extended to five colours. Here, one can see a clear rectangular array structure with each row containing all the shapes in one colour and each column containing all the colours for one shape. In Fig. 6 the sweaters $\left(M_{1}\right)$ and trousers $\left(M_{2}\right)$ have been drawn and combinations are shown by drawing lines between trousers and sweaters and writing names of days (abbreviated forms of the days of the week in Norwegian) above these lines 
Ms. Hall has 3 pairs of trousers and 5 sweaters. The trousers are in the colours blue, black, and grey. The sweaters are in the colours blue, red, black, green and purple. She will use one pair of trousers and one sweater each day, and she will combine different pairs of trousers with different sweaters. How many days in a row can Ms. Hall wear different outfits?

Fig. 3 Task 2

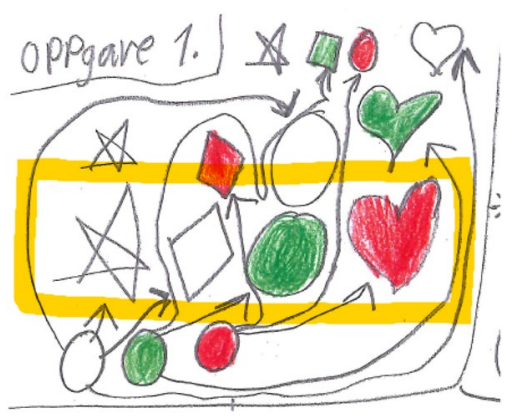

Fig. 4 An early solution of Task 1

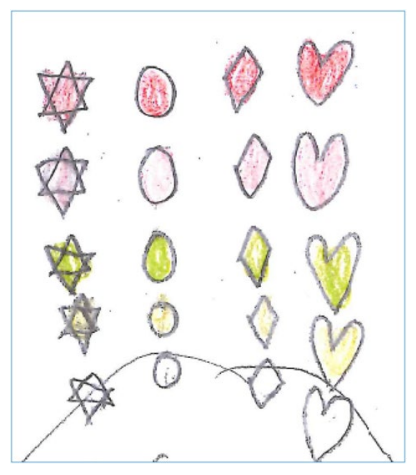

Fig. 5 A later solution of Task 1

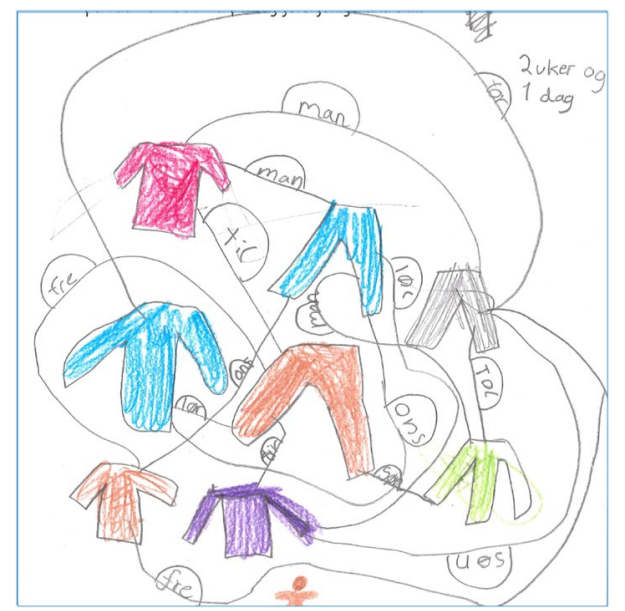

Fig. 6 A successful solution of Task 2
$\left(M_{3}\right)$. The pupils indicated their solution by writing " 2 uker og 1 dag" ( 2 weeks and 1 day) in the upper right corner. The pupils who made the drawing shown in Fig. 6 did find all combinations but not all pupils did so.

In these tasks, the target knowledge was that the pupils should see Cartesian products as a multiplicative structure, and also that they should be able to represent the solutions in a rectangular array. In Figs. 4 and 5 the rectangular array structure is clearly visible, whereas this is not the case in Fig. 6. I now present parts of a dialogue on Task 2 to show some of the challenges involved in seeing the multiplicative structure. One of the challenges with combinatorial problems is to find a stopping strategy (English 1991; Shin and Steffe 2009). A common stopping strategy turned out to be that the pupils could not find more combinations, but this strategy was often combined with attempts at a systematic count of combinations. In a conversation between Roger, Nora and one of the researchers Roger said that "we have been thinking that we can take all the sweaters with all the trousers and all the trousers with all the sweaters". From this he deduced that it would be "five sweaters times three, that is fifteen". This shows a systematic strategy, but when Nora showed on her drawing that she had found only 12 combinations, Roger did not trust his reasoning anymore and said to Nora, "so you were right, it was twelve, not fifteen". Later Nora discovered more combinations, and finally they found 15, and then Roger's faith in his initial thinking was restored:

Roger: So then it is fifteen. I was right. YES!

Researcher: How did you think when you found fifteen?

Roger: When I thought fifteen? Because three times five is fifteen.

Researcher: Why did you think three times five?

Roger: Because there are three pairs of trousers and then there are five sweaters. And all five sweaters can be used three times on each pair of trousers, no, one time on each pair of trousers.

The last utterance above seems to indicate that Roger has identified a multiplicative structure.

The excerpts above are from the phases that were intended to be adidactical. However, it can be seen that there are interventions from a researcher, and also the teacher participated in similar interventions. It can be criticised that 
through these interventions, the TDS design was not followed as it should be, but as researchers, we considered that it would be unethical not to help the pupils, and also some of the questions posed were asked in order to uncover pupils' language use. Using observations from the group work, the teacher started a didactical validation phase in the whole class, leading into the institutionalisation phase. She had observed that the pupils did not seem to realise that the two tasks had the same mathematical structure, so she expressed to the researchers that she wanted to establish the connection between the tasks in a whole class session. She started by referring to a written explanation given by Tara and George to a version of Task 1 with six shapes and three colours:

Our method is that we draw all the shapes and then draw two more below. Then we colour the shapes in the colours we are supposed to use. Then we count all the shapes. And in this task, there were 18 shapes.

The teacher asked the class why Tara and George had drawn three rows and Frank said, "because we have three colours", and Nora continued, "As many colours as there are, so many rows of shapes do we need". The teacher used this structure to introduce the notation $3+3+3+3+3+3$. They agreed that they had six $3 \mathrm{~s}$ and that this could be written $3+3+3+3+3+3=18$, or $6 \times 3=18$. Next, the teacher asked whether the pupils could see any similarities between the two tasks and the following dialogue took place.

Frank: One shape can be one sweater. And that shape you can take three times. And the sweater can be used three times since there are three pairs of trousers.

There were three colours on the biscuits also.

Teacher: Any more similarities?

Roger: Both times it was a 'times-task'.

Nadia: It was almost the same question, how many

different ... and we used the same method ...

Frank, in his utterance above, related the two tasks by saying that each shape can be used three times (original version of Task 1) and each sweater can be used three times (Task 2). After some discussion, the teacher showed her own representation (Fig. 7). Here statements like " 3 on each sweater" that the teacher had seen in the pupils' worksheets are represented with three rows, with five sweaters in each row. They agreed that this could be expressed as three times five or as five times three, and this was visualised by pupils coming to the board drawing curves around the columns and counting them, five times three, and afterwards drawing curves around the rows and counting three times five. A rectangular pattern had been established.

In the teaching sequences, the TDS design gave the teacher the opportunity to observe pupils' language and to build on these observations to connect the tasks and see them as parts of a larger pattern of multiplicative structures.

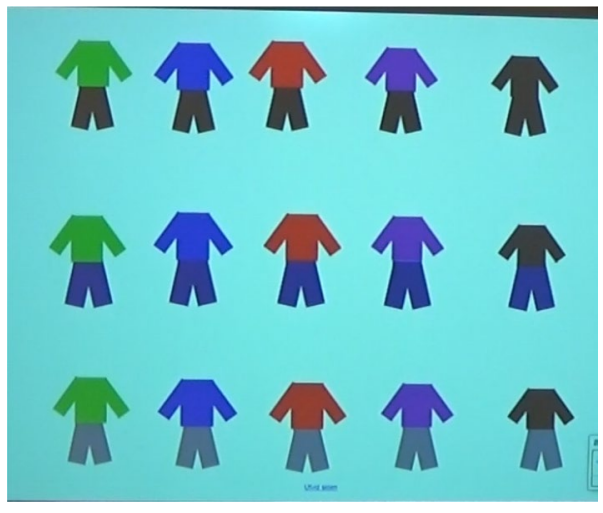

Fig. 7 The teacher's representation

As in Episode 1, there was insufficient feedback potential from the milieu (González-Martin et al. 2014), which led the teacher to introduce didactical elements.

\section{Summary and conclusion}

This paper is guided by the research question "What opportunities can a teaching design based on TDS give a teacher to gain insight into pupils' language use and to use this insight to establish shared, and mathematically acceptable, knowledge in a group of primary school pupils?" The analysis shows that, in particular, two aspects of the TDS design are important. The first aspect is the approach in the adidactical phases where the pupils engage with the material milieu and are free to express their thoughts and ideas in the language of their choice. This aspect has elements akin to those manifested in inquiry-based learning (Laursen and Rasmussen 2019). Part of this aspect is also that the teacher has the opportunity to observe the pupils' language and, based on these observations, she can make plans for didactical interventions at a later stage. The second aspect is exactly these didactical interventions. Guided by the defined target knowledge, the teacher designs a didactical validation and institutionalisation phase in which pupils' solution strategies and language are actively used, in interaction with the pupils, to establish a mathematically acceptable discourse. The result of this second phase is that, although allowing for an inquiry approach, the problems are under control of the teacher (Artigue and Blomhøj 2013).

Howe and Abedin (2013) found in their study that classroom dialogue was based mainly on a teacher-student IRF pattern and they advertised the need for more knowledge about modes of organisation that are more beneficial than others. Also Muhonen et al. (2016) concluded that little is known about concrete teaching practices that facilitate highquality classroom dialogue, especially among younger children. The present study shows that a design based on TDS 
can give opportunities to break out of the traditional IRF pattern, and that it can foster high-quality classroom dialogue, also among younger children, resulting in a successful encounter of everyday and scientific language (Vygotsky 1987). The teacher's active role in the didactical phases, combined with the well-defined target knowledge, allow for investigations that look at the language of the learner, the language of the teacher and the classroom, and the language of mathematics in an integrated way (Ingram et al. 2020; Schütte and Planas 2018). The study also confirms that children with monolingual and relatively schooled backgrounds benefit from language support (Schütte 2014, 2018; Prediger and Wessel 2018).

Admittedly, the design that I have described is not 'ideal', seen from a TDS perspective. An adidactical situation should be designed in such a way that the pupils can handle it without teacher intervention. The pupils should have prior knowledge sufficient to engage with the situation and the milieu should have sufficient feedback potential for the pupils to develop the knowledge aimed at by the teacher (González-Martín et al. 2014; Måsøval 2013; Strømskag 2017). In particular the lack of feedback potential was evident in both teaching sessions. Clearly the study is limited in the sense that it is based on observations from one class only. However, the span in time (age) and the variety of mathematical topics give reasons to believe that similar results could have been obtained also with other groups of pupils. One may criticise the intended adidactical phases for not being purely adidactical, but still I claim that I have been able to show that a TDS design is helpful for fostering language development aiming at conceptual knowledge and conceptual understanding (Hiebert and Carpenter 1992; Hiebert and Lefevre 1986; Moschkovich 2015; Prediger and Zindel 2017).

Acknowledgements The project LaUDiM is supported by the Research Council of Norway under project 238041. The author would like to thank the reviewers and the editor for very constructive and helpful comments.

Funding Open Access funding provided by NTNU Norwegian University of Science and Technology (incl St. Olavs Hospital - Trondheim University Hospital).

Open Access This article is licensed under a Creative Commons Attribution 4.0 International License, which permits use, sharing, adaptation, distribution and reproduction in any medium or format, as long as you give appropriate credit to the original author(s) and the source, provide a link to the Creative Commons licence, and indicate if changes were made. The images or other third party material in this article are included in the article's Creative Commons licence, unless indicated otherwise in a credit line to the material. If material is not included in the article's Creative Commons licence and your intended use is not permitted by statutory regulation or exceeds the permitted use, you will need to obtain permission directly from the copyright holder. To view a copy of this licence, visit http://creativecommons.org/licenses/by/4.0/.

\section{References}

Artigue, M. (2015). Perspectives on design research: The case of didactical engineering. In A. Bikner-Ahsbahs, C. Knipping, \& N. C. Presmeg (Eds.), Approaches to qualitative research in mathematics education. Examples of methodology and methods (pp. 467-496). Dordrecht: Springer.

Artigue, M., \& Blomhøj, M. (2013). Conceptualizing inquiry-based education in mathematics. ZDM - The International Journal on Mathematics Education, 45, 797-810.

Artigue, M., Haspekian, M., \& Corblin-Lenfant, A. (2014). Introduction to the theory of didactical situations (TDS). In A. Bikner-Ahsbahs \& S. Prediger (Eds.), Networking of theories as a research practice in mathematics education (pp. 47-65). Cham: Springer.

Bonwell, C. C., \& Eison, J. A. (1991). Active learning: Creating excitement in the classroom. 1991 ASHEERIC Higher Education Reports. Washington, DC: ERIC Clearinghouse on Higher Education.

Brousseau, G. (1997). The theory of didactical situations in mathematics: Didactique des mathématiques, 1970-1990 (N. Balacheff, M. Cooper, R. Sutherland, \& V. Warfield, Eds. \& Trans.). Dordrecht: Kluwer.

Bruder, R., \& Prescott, A. (2013). Research evidence on the benefits of IBL. ZDM - The International Journal on Mathematics Education, 45, 811-822.

English, L. D. (1991). Young children's combinatoric strategies. Educational Studies in Mathematics, 22, 451-474.

Erath, K., Ingram, J., Moschkovich, J., \& Prediger, S. (2021). Designing and enacting instruction that enhances language for mathematics learning - A review of the state of development and research. ZDM Mathematics Education, 53, in this issue.

Fischbein, E. (1993). The theory of figural concepts. Educational Studies in Mathematics, 24, 139-162.

Frege, G. (1892). Über Sinn und Bedeutung [On sense and reference]. Zeitschrift für Philosophie und philosophische Kritik, 100(1), 25-50.

Geach, P., \& Black, M. (Eds.). (1960). Translations from the philosophical writings of Gottlob Frege. Oxford: Basil Blackwell.

González-Martín, A. S., Bloch, I., Durand-Guerrier, V., \& Maschietto, M. (2014). Didactic situations and didactical engineering in university mathematics: Cases from the study of calculus and proofs. Research in Mathematics Education, 16(2), 117-134.

Greer, B. (1992). Multiplication and division as models of situations. In D. A. Grouws (Ed.), Handbook of research on mathematics teaching and learning (pp. 276-295). New York, NY: Simon \& Schuster Macmillan.

Hiebert, J., \& Carpenter, T. P. (1992). Learning and teaching with understanding. In D. A. Grouws (Ed.), Handbook of research on mathematics teaching and learning (pp. 65-97). New York, NY: Simon and Schuster Macmillan.

Hiebert, J., \& Lefevre, P. (1986). Conceptual and procedural knowledge in mathematics: An introductory analysis. In J. Hiebert (Ed.), Conceptual and procedural knowledge: The case of mathematics (pp. 1-27). Hillsdale, NJ: Lawrence Erlbaum.

Howe, C., \& Abedin, M. (2013). Classroom dialogue: A systematic review across four decades of research. Cambridge Journal of Education, 43(3), 325-356.

Ingram, J., Chesnais, A., Erath, K., Rønning, F., \& Schüler-Meyer, A. (2020). Language in the mathematics classroom: An introduction to the papers and presentations within ETC 7. In J. Ingram, K. Erath, F. Rønning, \& A. K. Schüler-Meyer (Eds.), Proceedings of the Seventh ERME topic conference on language in the mathematics classroom (pp. 5-12). Montpellier: University of Montpellier and ERME. 
Laursen, S. L., \& Rasmussen, C. (2019). I on the prize: Inquiry approaches in undergraduate mathematics. International Journal of Research in Undergraduate Mathematics Education, 5, $129-146$.

Måsøval, H. S. (2013). Shortcomings in the milieu for algebraic generalisation arising from task design and vagueness in mathematical discourse. In C. Margolinas (Ed.), Task design in mathematics education. Proceedings of ICMI Study 22 (pp. 231-239). Oxford: The International Commission on Mathematical Instruction.

Moschkovitch, J. N. (2015). Academic literacy in mathematics for English learners. The Journal of Mathematical Behavior, 40(A), 43-62.

Muhonen, H., Rasku-Puttonen, H., Pakarinen, E., Poikkeus, A.-M., \& Lerkkanen, M.-K. (2016). Scaffolding through dialogic teaching in early school classrooms. Teacher and Teacher Education, 55, $143-154$

Prediger, S., \& Wessel, L. (2013). Fostering German-language learners' constructions of meanings for fractions-design and effects of a language- and mathematics-integrated intervention. Mathematics Education Research Journal, 25(3), 435-456.

Prediger, S., \& Wessel, L. (2018). Brauchen mehrsprachige Jugendliche eine andere fach- und sprachintegrierte Förderung als einsprachige? [Do multilingual young people need different subjectand language-integrated support compared to monolinguals?]. Zeitschrift für Erziehungswissenschaft, 21(2), 361-382.

Prediger, S., \& Zindel, C. (2017). School academic language demands for understanding functional relationships - a design research project on the role of language in reading and learning. Eurasia Journal of Mathematics Science and Technology Education, 13(7b), 4157-4188.

Schütte, M. (2014). Language-related learning of mathematics: a comparison of kindergarten and primary school as places of learning. ZDM - The International Journal on Mathematics Education, 46, 923-938.

Schütte, M. (2018). Subject-specific academic language versus mathematical discourse. In J. N. Moschkovich, D. Wagner, A. Bose, J. R. Mendes, \& M. Schütte (Eds.), Language and communication in mathematics education. International perspectives (pp. 25-36). Cham: Springer.

Schütte, M., \& Planas, N. (2018). ETC4 Introduction. The research force and community behind ETC4 and the conference proceedings. In N. Planas \& M. Schütte (Eds.), Proceedings of the fourth ERME topic conference 'language in the mathematics classroom-based research on mathematics and language' (pp. 5-6). Dresden: Technical University of Dresden and ERME.

Shin, J., \& Steffe, L. P. (2009). Seventh graders' use of additive and multiplicative reasoning for enumerative combinatorial problems. In S. L. Swars, D. W. Stinson, \& S. Lemons-Smith (Eds.), Proceedings of the 31st annual meeting of the North American chapter of the international group for the psychology of mathematics education (Vol. 5, pp. 170-177). Atlanta, GA: Georgia State University.

Strømskag, H. (2017). A methodology for instructional design in mathematics-with the generic and epistemic student at the centre. ZDM Mathematics Education, 49, 909-921.

Vergnaud, G. (1983). Multiplicative structures. In R. Lesh \& M. Landau (Eds.), Acquisition of mathematics concepts and processes (pp. 127-174). Orlando, FL: Academic Press.

Vergnaud, G. (1996). The theory of conceptual fields. In L. P. Steffe, P. Nesher, P. Cobb, G. A. Goldin, \& B. Greer (Eds.), Theories of mathematical learning (pp. 219-239). Mahwah, NJ: Lawrence Erlbaum.

Verschaffel, L., Schukajlow, S., Star, J., \& Van Dooren, W. (2020). Word problems in mathematics education: A survey. ZDM Mathematics Education, 52, 1-16.

Vygotsky, L. S. (1978). Mind in society: The development of higher psychological processes (M. Cole, V. John-Steiner, S. Scribner, \& E. Souberman, Eds.). Cambridge, MA: Harvard University Press.

Vygotsky, L. S. (1987). Thinking and speech (N. Minick, Trans.). In R. W. Rieber \& A. S. Carton (Eds.), The collected works of L. S. Vygotsky: Vol. 1. Problems of general psychology (pp. 39-285). New York, NY: Plenum Press.

Wertsch, J. V. (1991). Voices of the mind. A sociocultural approach to mediated action. Cambridge, MA: Harvard University Press.

Publisher's Note Springer Nature remains neutral with regard to jurisdictional claims in published maps and institutional affiliations. 